\title{
Influence of foliation on excavation stability at Rampura Agucha underground mine
}

\author{
P Yadav, A Panda, M Sonam, B Banerjee, S Parihar, and DC Paneri \\ Geotechnical Department, Rampura Agucha Mine \\ Rajasthan India \\ amit.panda@vedanta.co.in
}

\begin{abstract}
Rampura Agucha mine is exploiting the world's largest $\mathrm{Pb}-\mathrm{Zn}$ deposit and is currently in progress of transitioning from open cast to underground mining. Underground ore access development is primarily developed through foliated strata of a moderate strength which pose many challenges. Rock mass response in foliated ground depends on several factors including in-situ stress conditions, orientation of excavation with respect to foliation planes, excavation geometry and blasting practices. Presented study utilizes a numerical code FLAC3D and ubiquitous joint constitutive model to gain insights into excavation stability in a foliated rock mass. Historical observations of drives damage and measurements from geotechnical instrumentation were utilized to calibrate the numerical models. A comprehensive conceptual modeling study was carried out to analyze the rock mass failure mode due to varying inter-plane angle between foliation strike and excavation walls and depth of excavation. Modeling results were summarized into a quantitative damage classification scheme which is being used by the mine geotechnical department to predict rock mass response, depth of failure around excavation, ground support and rehabilitation requirements.
\end{abstract}

Keywords - foliated rock mass, excavation stability, numerical modeling, ubiquitous joint and damage classification scheme.

\section{INTRODUCTION}

The Rampura Agucha deposit forms a part of pre-Aravalli Banded Gneissic Complex consisting of gneisses, schist and intrusive of acidic and basic igneous rocks that occupy, predominantly, the south eastern plains of Ajmer and Bhilwara.

Country rock found at RAM comprises primarily of Garnet - Biotite - Silimanite - Schist/Gneiss (GBSS/GBSG). Typical GBSG/GBSS is strongly foliated. Foliation within is defined by layered arrangement of flaky and fibrous mineral around the garnet. Foliated rocks tend to fail or yield at relatively low stress levels and exhibit 'high deformation' behavior. This paper aims to introduce a guideline for numerical model interpretation based on authors' field experience, geotechnical monitoring and numerical modeling at RAUG.

\section{MODELING APPROACH}

3D numerical modeling in explicit finite deference code FLAC3D (Itasca Consulting Group) was used to investigate the influence of foliation on drive stability. A series of numerical models were generated, examining the influence of foliation on drives parallel to strike of foliation at different depths. Two cases i.e. unsupported drives and supported drives were simulated in numerical models at each depth.

Material properties used in the models were based on laboratory and in-situ testing campaigns carried out at site. Models were calibrated based on data generated from geotechnical instrumentation (Tape Extensometer) and visual observation of underground excavations.

Models were interpreted using damage classification scheme proposed by AMC / vakili, Australia during life of mine design of RAM UG.

\section{MODEL DESCRIPTION}

In-built grid generator of FLAC3D 5.0 was used to create model geometry. Primitive mesh shapes of radially graded cylinder (radcylinder) and radially graded tunnel (radtunnel) was used to form a complete drive model.

\section{A. Model Geometry and Boundary Conditions}

The size of model was chosen to be $60 \times 60 \times 60 \mathrm{~m}$ (length $\mathrm{x}$ width $\mathrm{x}$ height) see Fig. 1a and a typical drive geometry of footwall drives and declines (5.6m wide and $5.3 \mathrm{~m}$ high) at RAM UG was chosen for this analysis see Fig. 1b. For increased precision, radially graded mesh around excavation was used with zone size of $0.5 \mathrm{~m}$ near excavation boundary and zone size of $5 \mathrm{~m}$ towards the external boundary. Roller boundary conditions were used on the vertical and bottom boundaries of the model, whereas vertical stresses were applied at the top boundary to simulate overburden above the box.

\section{B. Extraction and Ground Support Sequence}

Each model was first solved to achieve equilibrium with in-situ stresses and boundary conditions applied. For unsupported drive simulations, following the equilibrium state the drive was extracted and models were solved to achieve equilibrium without any ground support installed. For supported drive simulations, following the equilibrium state the drive was extracted and ground support was installed after prescribed amount of deformation and then models were solved to achieve equilibrium. In the model, the shotcrete was applied from floor to floor of the drive and rock bolts were installed in roof and sidewalls of the excavation on a $1.2 \times 1.2$ $\mathrm{m}$ grid pattern. 


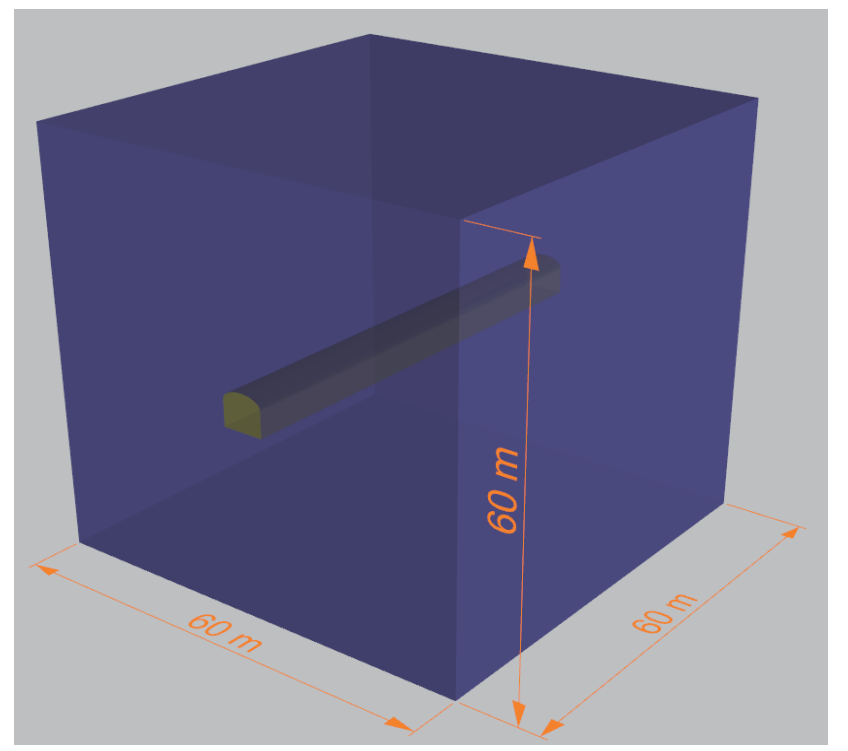

(a)

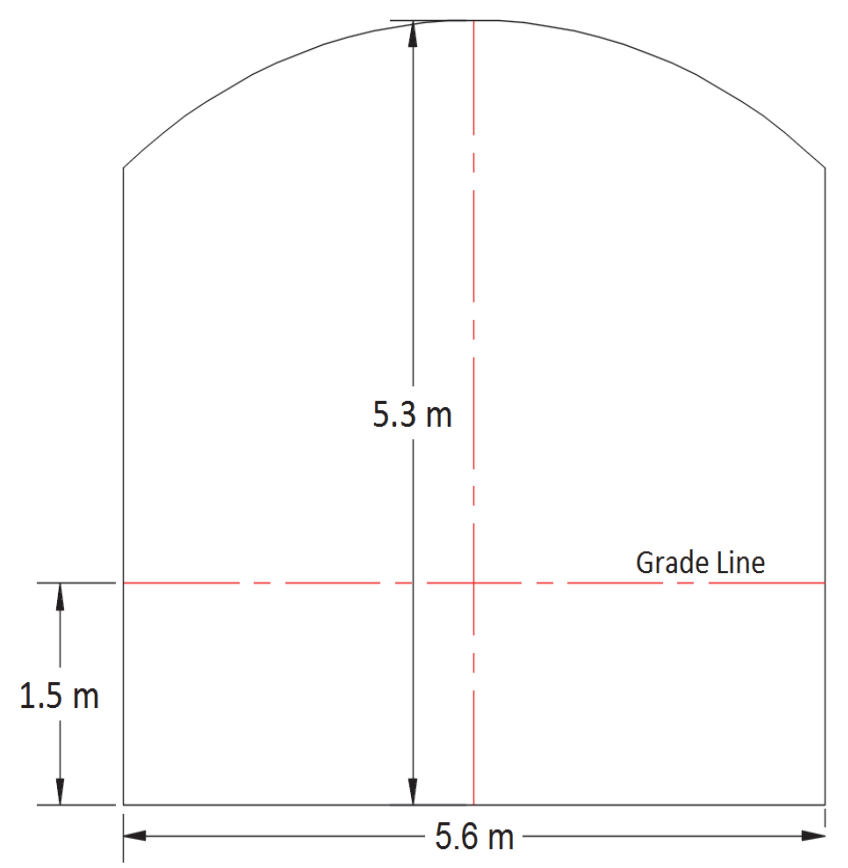

(b)

Fig. 1 - (a) Geometry of 3D model, (b) Drive geometry

\section{In-situ Stress Field}

In-situ stress fields used for modeling were based on Hydraulic Fracturing (HF) stress measurement results undertaken at RAM UG.

In the model far-field stresses were applied at the boundaries which were sufficiently representative and the boundaries were kept far enough away so that they do not interact with the deformation field around the excavation.

The far-field stress boundary conditions used for this study are provided in equations below:

$$
\sigma_{\mathrm{H}}=\sigma_{\mathrm{yy}}=6.56+0.034 * \mathrm{H}
$$

$$
\begin{aligned}
& \sigma_{\mathrm{h}}=\sigma_{\mathrm{xx}}=1.73+0.017 * \mathrm{H} \\
& \sigma_{\mathrm{v}}=\sigma_{\mathrm{zz}}=0.028 * \mathrm{H}
\end{aligned}
$$

In these equations, $\sigma_{H}$ is the maximum horizontal stress in North - South direction, $\sigma_{h}$ is the minimum horizontal stresses in East-West direction and $\sigma_{v}$ is the vertical stress and $\mathrm{H}$ is the depth below the ground surface in meters.

\section{Constitutive Model, Rock mass and Ubiquitous Joint Properties}

The 3D numerical analysis was carried out utilizing Ubiquitous-Joint model which can incorporate the weaker foliation within GBSG/GBSS domain in FLAC3D.

\section{E. Constitutive Mode Description}

The Ubiquitous-Joint model accounts for the presence of an orientation of weakness (weak plane) in a FLAC3D MohrCoulomb model. The criterion for failure on the plane whose orientation is given, consists of a composite Mohr-Coulomb envelop with tension cutoff. The position of a stress point on the later envelope is controlled again by a non-associated flow rule for shear failure and an associated rule for tension failure.

In this numerical model, general failure is first detected, and relative plastic corrections are applied. The new stresses are then analyzed for failure on the weak plane and updated accordingly.

\section{F. Rock Mass Properties}

Rock mass properties used in the model were derived from the GSI classification system and Hoek-Brown strength criterion. Intact rock properties were assessed from lab testing of core samples and rock mass characteristics were assessed from geotechnical mapping of the underground excavations. Rock mass properties were then derived using RocData (Rocscience Inc.) which uses empirical relations and guidelines to provide representative rock mass properties.

The rock mass properties were chosen to best represent GBSG/GBSS domain at RA-UG of fair quality rock. Rock mass properties used in the models are listed in Table I.

\section{G. Ubiquitous Joint Properties}

Non-linear, Barton-Bandis failure criterion was used to estimate the shear strength of ubiquitous joint (foliation). Characteristics of ubiquitous joint were assessed from geotechnical mapping of underground drives and core logging of diamond drill holes. The properties of ubiquitous joint used for simulating foliation are provided in the Table II.

\section{H. Rock bolt and Fiber Reinforced Shotcrete Properties}

Typically RAM - UG utilizes a combination of $25 \mathrm{~mm}$ diameter, $2.4 \mathrm{~m}$ long fully grouted resin bolts and $50-100 \mathrm{~mm}$ layer of sprayed fiber reinforced shotcrete for primary ground support of footwall drives and declines. 
Resin bolts were simulated in the models utilizing "cable" structural element and fiber reinforced shotcrete was simulated utilizing “liner' structural elements.

TABLE I - ROCK MASS PROPERTIES

\begin{tabular}{|lccc|}
\hline \multicolumn{4}{|c|}{ Rock Mass Properties for GBSG / GBSS } \\
\hline Property & Symbol & Value & Unit \\
\hline Young's modulus & $\mathrm{E}_{\mathrm{m}}$ & 6.24 & $\mathrm{GPa}$ \\
Poisson's ration & $v_{\mathrm{m}}$ & 0.25 & - \\
Bulk modulus & $\mathrm{K}_{\mathrm{m}}$ & $4.16^{*}$ & $\mathrm{GPa}$ \\
Shear modulus & $\mathrm{G}_{\mathrm{m}}$ & $2.50^{*}$ & $\mathrm{GPa}$ \\
Density & $\rho_{\mathrm{m}}$ & 2800 & $\mathrm{~kg} / \mathrm{m} 3$ \\
Cohesion & $\mathrm{c}_{\mathrm{m}}$ & 2.4 & $\mathrm{MPa}$ \\
Friction angle internal & $\emptyset_{\mathrm{m}}$ & $49.6^{\circ}$ & Degree \\
Tensile strength & $\sigma_{\mathrm{tm}}$ & 0.12 & $\mathrm{MPa}$ \\
Dilation Angle & $\psi_{\mathrm{m}}$ & $0^{\circ}$ & Degree \\
\hline
\end{tabular}

TABLE II - UBIQUITOUS JOINT PROPERTIES

\begin{tabular}{|l|c|l|l|}
\hline \multicolumn{4}{|c|}{ Ubiquitous Joint Properties for Foliation } \\
\hline Parameter & Symbol & Value & Unit \\
\hline Joint cohesion & $c_{j}$ & 0.21 & $\mathrm{MPa}$ \\
Joint dip & $d_{j}$ & $70^{\circ}$ & Degree \\
Joint dip direction & $d d_{j}$ & $90^{\circ}$ & Degree \\
Joint dilation & $\psi_{j}$ & $0^{\circ}$ & Degree \\
Joint friction & $\emptyset_{j}$ & $33.3^{\circ}$ & Degree \\
Joint tension & $\sigma_{t j}$ & 0.32 & MPa \\
\hline
\end{tabular}

I. Resin Bolts - Cable Structural Elements:

In FLAC3D "cable" structural elements are defined by their geometry, material and grout properties. These elements behave as elastic, perfectly plastic material that can yield in tension and compression, but cannot resist a bending moment. Material properties of resin bolts were derived from lab testing results of the resin bolt rebar. In addition to geometry and mechanical properties two grout properties are also required to represent grout characteristics in FLAC3D and they are "K-bond" which represents stiffness of the grout and "S-bond" which represents grout cohesive strength.

K-bond or grout stiffness depends on grout properties and the annulus thickness. The FLAC3D manuals suggest that the following expression can be used for a practical and reasonable estimated of $\mathrm{K}$-bond

$$
\mathrm{K}-\text { bond } \cong \frac{2 \pi G}{10 \ln (1+2 \mathrm{t} / \mathrm{D})}
$$

Where, $\mathrm{G}$ is the grout shear modulus, $\mathrm{D}$ is bolt diameter and $t$ is the annulus thickness.
Farmer reports a value of $2.25 \mathrm{GPa}$ for Young's modulus of resin grout. For a typical $25 \mathrm{~mm}$ rock bolt in a $35 \mathrm{~mm}$ drillhole, K-bond is approximately $1.5 \times 1010 \mathrm{~N} / \mathrm{m} 2$.

S-bond or grout cohesive strength depends on likely failure mode of the resin bolt anchor. If resin grout is week, shear failure occurs along the bolt grout interface. S-bond depends on the grout cohesion and the perimeter of the resin bolt. Framer reports a value of $160 \mathrm{Mpa}$ for the compressive strength of resin grout. The FLAC3D manual suggests that when failure is expected to occur at the bolt / grout interface following expression can be used for estimation of S-bond

$$
\mathrm{S}-\text { bond }=\pi * \mathrm{D} * \tau_{\text {peak }}
$$

Where, D is diameter of the bolt, $\tau_{\text {peak }}$ is peak shear strength which can be approximated using following expression

$$
\tau_{\text {peak }}=\tau_{1} * Q_{B}
$$

Where, $\tau_{1}$ is approximately one-half of the uniaxial strength of the weaker of the rock and grout, and $Q_{B}$ is the quality of the bond between the grout and rock $\left(Q_{B}=1\right.$ for perfect bonding).

The properties for resin bolts used in the model are listed in Table III.

TABLE III - RESIN BOLT PROPERTIES

\begin{tabular}{|l|c|c|c|}
\hline \multicolumn{4}{|c|}{ Resin Bolt Properties } \\
\hline Property & Symbol & Value & Unit \\
\hline Bolt Length & $\mathrm{l}$ & 2.4 & $\mathrm{~m}$ \\
Bolt Spacing (c-c) & $\mathrm{s}$ & 1.2 & $\mathrm{~m}$ \\
Bolt Diameter & $\mathrm{D}_{\mathrm{b}}$ & 25 & $\mathrm{~mm}$ \\
Borehole Diameter & $\mathrm{D}_{\mathrm{bh}}$ & 35 & $\mathrm{~mm}$ \\
Young's Modulus & $\mathrm{E}_{\mathrm{b}}$ & 200 & $\mathrm{GPa}$ \\
Poisson's Ratio & $\mathrm{v}_{\mathrm{b}}$ & 0.25 & - \\
Density & $\rho_{\mathrm{b}}$ & 7800 & $\mathrm{~kg} / \mathrm{m} 3$ \\
Tensile Yield Strength & $\mathrm{y}_{\mathrm{t}}$ & 250 & $\mathrm{kN}$ \\
Grout Cohesion (S-bond) & $\mathrm{c}_{\mathrm{g}}$ & $1 \mathrm{e} 8$ & $\mathrm{~N} / \mathrm{m}$ \\
Grout Stiffness (K-bond) & $\mathrm{k}_{\mathrm{g}}$ & $1.5 \mathrm{e} 10$ & $\mathrm{~N} / \mathrm{m} 2$ \\
& & & \\
\hline
\end{tabular}

\section{J. Fiber Reinforced Shotcrete Liner Structure}

Elements:Fiber reinforced shotcrete is simulated as a collection of "liner" structural elements in FLAC3D that are attached to the surface of the grids and provide structural behavior, a shear directed (in the tangent plane to the liner surface) frictional interaction between the liner and FLAC3D grid. Shotcrete properties used for numerical models are provided in table IV. 
TABLE IV - FIBER REINFORCED SHOTCRETE PROPERTIES

\begin{tabular}{|lclll|}
\hline \multicolumn{4}{|c|}{ Fiber Reinforced Shotcrete Properties } \\
\hline Property & Symbol & Value & Unit \\
\hline Density & $\rho_{\mathrm{s}}$ & 2500 & $\mathrm{~kg} / \mathrm{m} 3$ \\
Young's Modulus & $\mathrm{E}_{\mathrm{s}}$ & 17 & $\mathrm{GPa}$ \\
Poisson's Ratio & $\mathrm{v}_{\mathrm{s}}$ & 0.25 & - \\
Thickness & $\mathrm{t}_{\mathrm{s}}$ & 100 & $\mathrm{~mm}$ \\
Cohesion & $\mathrm{c}_{\mathrm{s}}$ & 7.5 & $\mathrm{MPa}$ \\
Friction Angle & $\emptyset_{\mathrm{s}}$ & 37 & Degree \\
Tensile Strength & $\sigma_{\mathrm{ts}}$ & 2.9 & $\mathrm{MPa}$ \\
\hline
\end{tabular}

\section{MODEL CALIBRATION AND INTERPRETATION}

\section{A. Model Calibration}

Numerical models were calibrated using geotechnical instrumentation data and observational mapping of drive damages carried out at RAM UG over the past years.

Geotechnical monitoring utilizing Tape extensometer was carried out for drives at varying orientation with respect to foliation planes.

Damage mapping of all underground excavations was carried out. Location of failure, mode of failure, ground support installed was recorded for each failure and drive damage.

\section{B. Model Interpretation}

Based on past experience of underground observations and numerical modeling carried out for RAM UG by AMC, a damage classification scheme was developed that can relate the observed underground damage and rehabilitation history to the displacement monitoring data and numerical modeling output parameters. The classification is provided in Table 5. This classification scheme was used to relate the expected damage levels to strain values obtained from FLAC3D results. The strain values used here is the minor principal strain $\left(\varepsilon_{3}\right)$, which is generally tensile after rock mass failure and directed normal to the excavation boundary. This strain value is considered to be the best indicator of rock mass damage. This strain is also equivalent to closure strains which can be easily measured in underground excavations by geotechnical monitoring (tape-extensometer)

\section{RESULTS}

The results of numerical models are summarized below.

\section{A. Mode of failure in foliated rock mass}

Numerical models suggest for a given strass level higher strain levels and displacements should be expected at two locations of a drive prallel to foliation planes, see Fig. 2.

Geotechnical monitoring and damage mapping of underground excavations suggests that foliated rocks tend to fail at low stress levels and separates from the wall in form of slabs. In a drive parallel to foliation planes two major types of failure has been recorded at RAM - UG i.e. "sliding" and "toppling". "Sliding" failures are common on the Western wall of a drive parallel to foliation and "toppling" failures are common on the Eastern wall of a drive parallel to foliation, see Fig. 3 to 5.

\section{B. Effect of depth}

Increase in depth of a drive results in increased in-situ stress levels. Numerical models suggest that with increase in depth the damage level of drive will also increase. The results are shown in Fig. 6 and Fig. 7.

Based on Table 5 and Fig. 4 and 5 it can be inferred that

- Drives at depth lesser than $\sim 500 \mathrm{~m}$ will experience minor damages with drive closure between $10-17$ $\mathrm{mm}$.

- Drives at depth of between $\sim 500-900 \mathrm{~m}$ from the surface will experience moderate damage and drive closure between $17-37 \mathrm{~mm}$. potential fall of intermediate wedges or blocks of edge length approximately between $20-50 \mathrm{~cm}$ should be expected during development and service life.

- Drive placed at more than $900 \mathrm{~m}$ depth will experience significant rock mass damage with drive closure of $>47 \mathrm{~mm}$, in these drives surface slabbing, spalling and major squeezing should be expected with potential fall of large wedges or blocks with edge length approximately greater than $50 \mathrm{~cm}$.

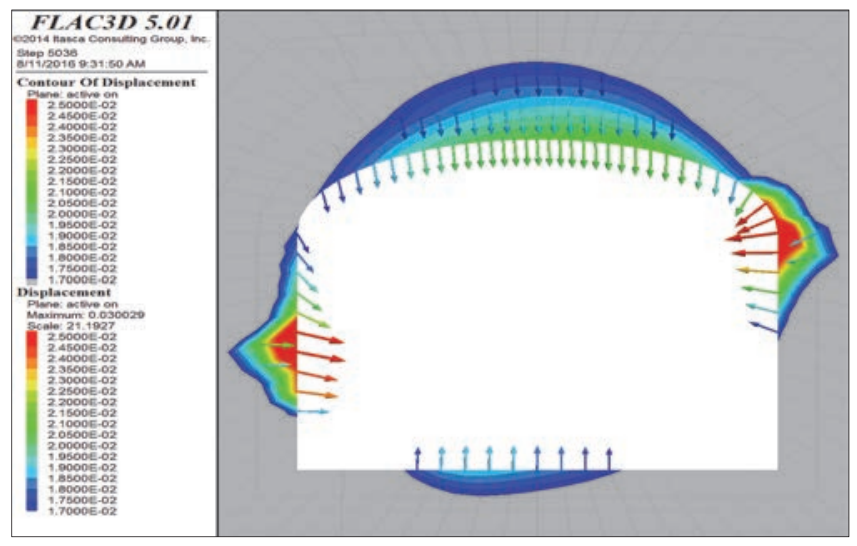

Fig. 2 - Contours and vectors of displacement in unsupported model at $500 \mathrm{~m}$ depth.

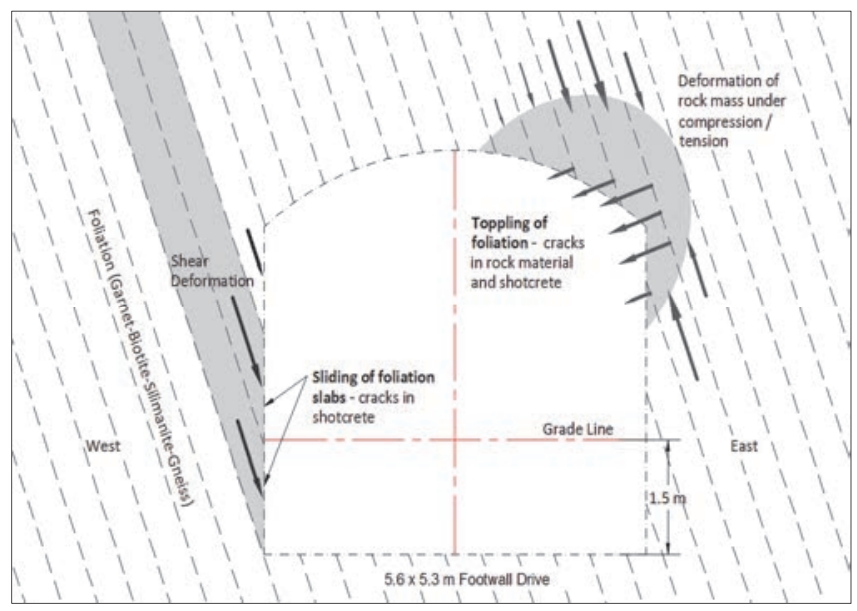

Fig. 3 - Typical rock mass behaviour of drive parallel to foliation 


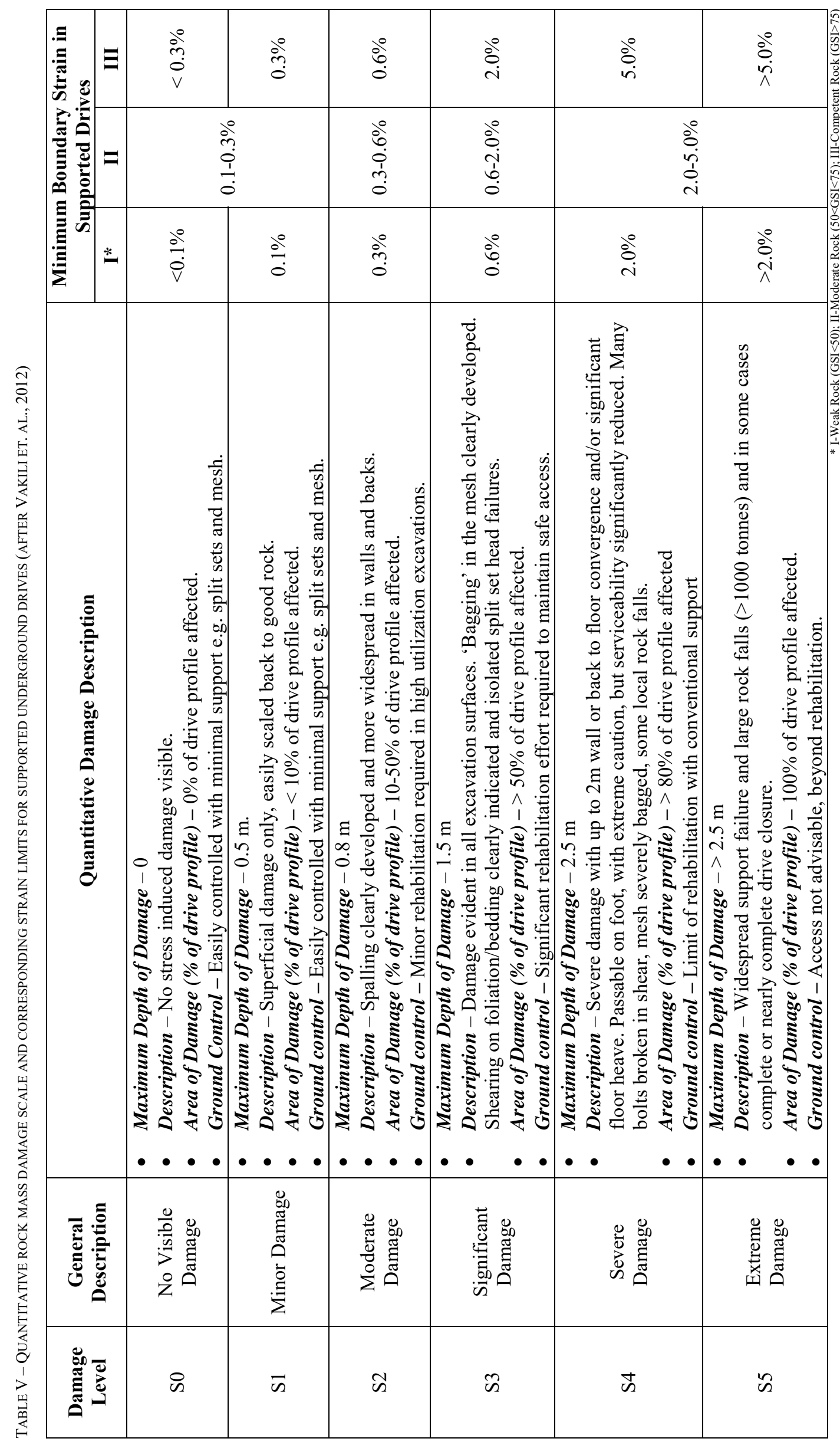




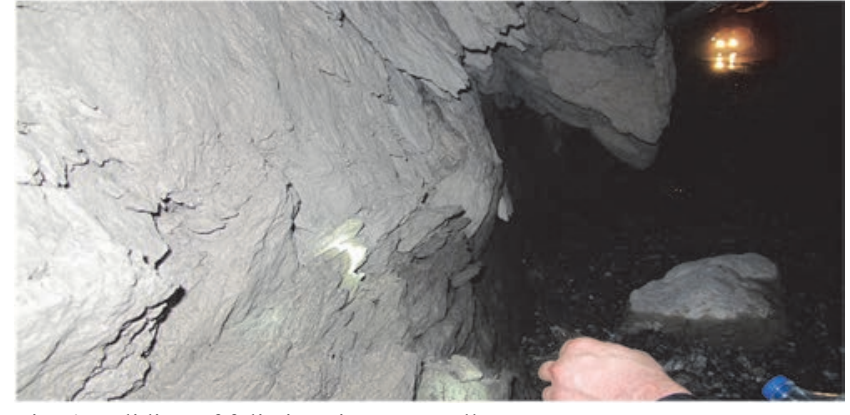

Fig. 4 - Sliding of foliations in West wall.

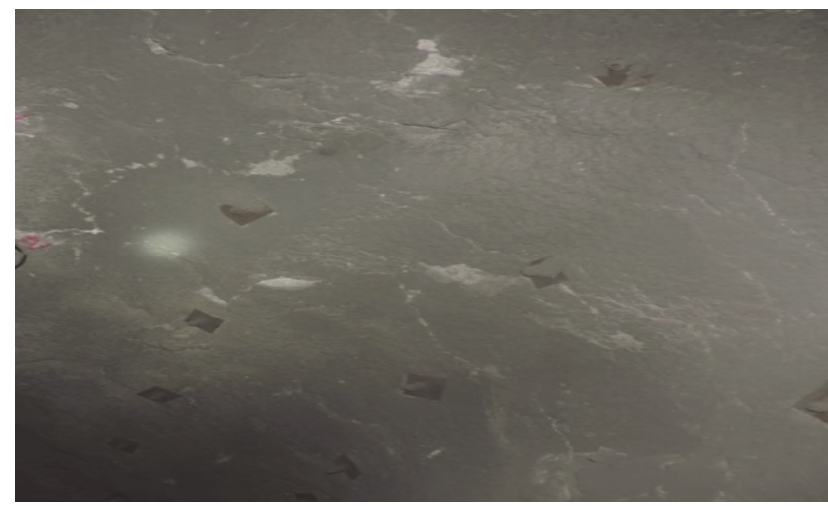

Fig. 5 - Toppling of foliations in East wall.

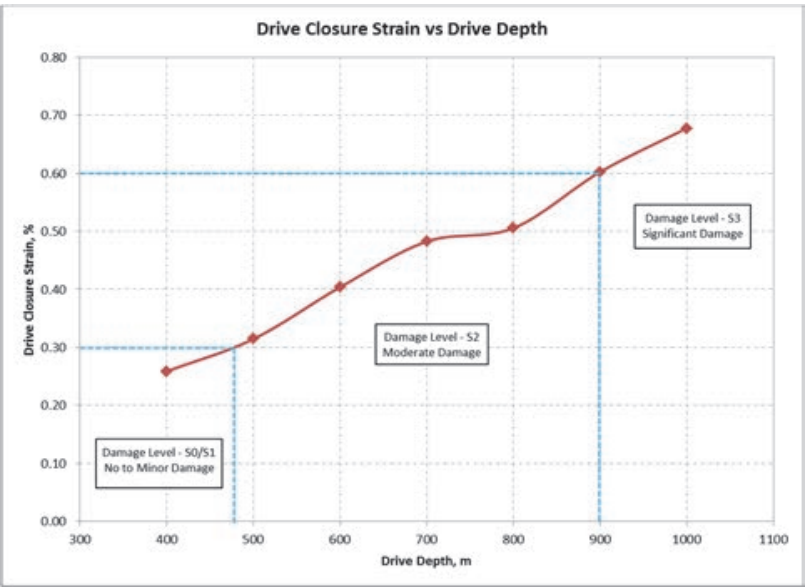

Fig. 6 - Effect of depth on drive closure strain.

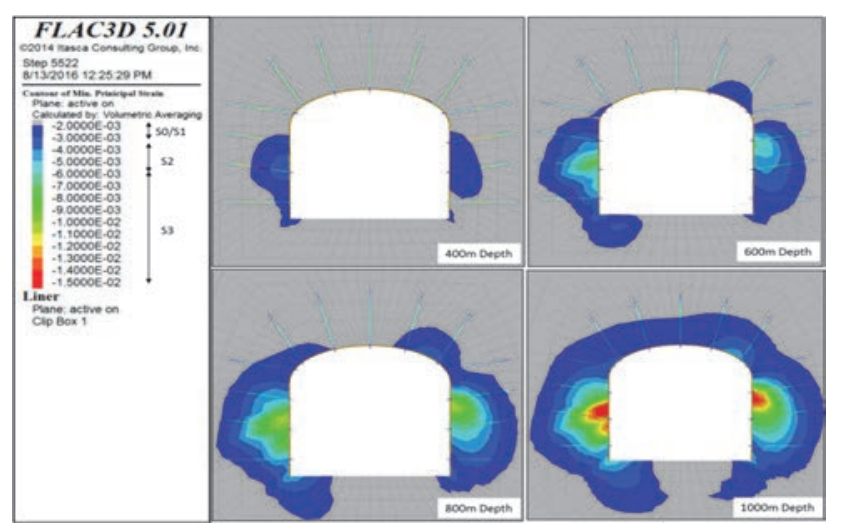

Fig. 7 - Contour of minimum principal strain around drive at different depths.

\section{CONCLUSION AND DISCUSSIONS}

The influence of foliation on excavation stability was analyzed for $5.6 \mathrm{~m}$ wide and $5.3 \mathrm{~m}$ high excavation for RAM UG using 3D numerical modeling.

The results of numerical models when compared to underground observation in the field and geotechnical monitoring data were found comparable.

Numerical analysis suggests that for a given stress levels moderate to significant rock mass damage should be expected when drives are extracted parallel of foliation orientations. These drives will require continuous rehabilitation works throughout its service life.

Also, significant rock mass damage should be expected in the excavations parallel to the foliation orientation below the depth of $600 \mathrm{~m}$ from surface. Drives below $600 \mathrm{~m}$ depth would require regular rehabilitation. Ground support designs for these drives should be meticulously done considering ability of support system to withstand large deformations.

Further comprehensive modeling should be carried out to simulate different orientation of the drive compared to the strike of the foliation.

The numerical analysis carried out in this study does not include the effect of stress redistributions due to open pit movement. Further comprehensive numerical modeling should be carried out to assess this effect of excavations stability.

\section{ACKNOWLEDGEMENT}

The authors would like to thank senior management of Hindustan Zinc Limited including Unit Head, Location head of Rampura Agucha for allowing us to access the geotechnical data from RA-UG mine and giving us the time to carry out this analysis. Authors would also like to thank Dr. Alexander Vyazmensky for providing valuable feedback and comments on this paper.

\section{REFERENCES}

1. Mishra A.K., Panigrahi D.C., Behera P.K., Sinha R.K., and Munshi B. (2015). Test Report "Geotechnical Lab Testing of Drill Core Samples From RA Mine, HZL".

2. Vakili A. and Teet R. (2014). AMC Report "Rampura Agucha Numerical Modelling Support".

3. Vakili A., Sandy M., Mathews M. and Rodda B. (2013) Ground Support Under Highly Stressed Condition".

4. Vakili A., Sandy M. and Alberecht J. (2012) "interpretation of nonlinear Numerical Models in Geomechanics - a case study in the Application of Raise Bored Shaft Design in Highly Stressed and Foliated Rock Mass".

5. Messy (2011). Rampura Agucha Mine Project (Hydraulic and HF Test).

6. Flac 3D 5.0 Manual. 